\title{
Water pollution issues and concerns in the Pacific Northwest, USA
}

\author{
R. Mahler ${ }^{1}$, M. Barber ${ }^{2}$ \& B. Shafii ${ }^{3}$ \\ ${ }^{I}$ Soil and Environmental Sciences, University of Idaho, USA \\ ${ }^{2}$ Department of Civil Engineering, University of Utah, USA \\ ${ }^{3}$ Department of Plant, Soils and Entomological Sciences, \\ University of Idaho, USA
}

\begin{abstract}
Over $90 \%$ of Pacific Northwest residents consider safe drinking water, clean rivers and groundwater protection to be the three most important environmental issues in the region. Consequently, pollution prevention is the key to protect these water-related issues. Public input has been sought on a regular basis (2002, 2007 and 2012) to identify major pollution sources of concern. Statistically designed regional surveys conducted at five-year intervals identified industry as the pollution source of most concern. In addition 32.0, 30.5, 29.2 and $25.5 \%$ of the public identified animal production, crop production, storm water runoff and erosion due to roads and construction as significant sources of water pollution, respectively. Fewer than $18 \%$ of survey respondents considered runoff from home landscapes, wastewater treatment plants, landfills, forestry, mining and military bases as being major polluters. The demographic factors of state of residence, community size, gender and highest level of formal education significantly impacted the responses from citizens surveyed. The public ranking of pollution sources do not match data collected at the state level. Public education should be modified to appropriately proportionally address pollution sources based on their actual harm to water resources.
\end{abstract}

Keywords: public opinion, pollution issues, pollution concerns, adult education, public outreach. 


\section{Introduction}

The quality of surface waters on planet Earth generally declines with increased human activity in the vicinity of the water resource. Several studies have shown a relationship between increased human populations and declines in the quality of surface waters including streams, rivers, lakes, wetlands, estuaries, bays and coastal oceans. In temperate regions of the world both animal agriculture and cropping systems agriculture usually negatively impact surface waters [1]. Agriculture contributes to decreased surface water quality through the introduction of sediments and runoff of nutrients and pesticides into these waters [2-4].

Agriculture however, is not alone in contributions of sediments, nitrogen and phosphorus to surface waters as other human activities including forestry, mining, industry, military bases, septic systems, and waste water treatment have also been implicated through research studies [5]. In rapidly urbanizing areas of the world, including the Puget Sound region of western Washington state, wetlands, rivers, estuaries and bays have become polluted [6]. In these urban areas storm water runoff, runoff from home landscapes, and new suburban development have also been linked to decreased surface water quality $[6,7]$. Both roads and road construction have been widely implicated in reducing water quality of rivers and lakes throughout the world $[8,9]$.

The protection of planet Earth's water resources has been a paramount environmental issue in the scientific community for several decades. To achieve this many governments have resorted to a regulatory approach to deal with these complex issues; however, this approach has not always yielded the desired outcomes. Consequently, a groundswell of support for voluntary actions to protect water resources has emerged [10]. Several studies have shown that this mixed approach - both regulatory and voluntary actions work best [11]. Yet others have called for the integration of voluntary, regulatory and economic strategies to protect both the quality and quantity of water resources [12]. No matter the type of approach taken to protect water resources success ultimately depends on the involvement of key stakeholder groups at the beginning of the protective effort [13].

Since 1987 in the USA an increased emphasis has been placed on public education as a mechanism to improve the nation's water resources through voluntary actions. This idea has been implemented using a regional rather than a state-by-state approach. To accurately determine the effectiveness of regional programming, it is important both to establish base-line information about public perceptions and literacy, and then to measure change in public attitudes and actions over time. Furthermore, to identify the best opportunities for successful regional programming, it is imperative to understand the similarities and differences that exist among the target audiences. In the four-state (Alaska, Idaho, Oregon, Washington) Pacific Northwest Region, a survey instrument was developed to provide base-line information on public attitudes regarding water resources in 2002 from which future Extension programming outcomes can be measured $[14,15]$. This initial regional survey documented public attitudes about 
water resources in 2002. At that time it was anticipated that follow-up water resource surveys would be conducted at 5- (2007), 10- (2012), 15- (2017), 20(2022) and 25- (2027) year intervals. This paper evaluates information about public perceptions about the human activities that significantly contribute to pollution of surface waters in the region based on the 2012 10-year follow up survey. This paper summarizes and discusses the activities that the public in the Pacific Northwest blames most for poor surface water quality. This paper will try to see if there is a genuine link between public perceptions about polluters and the existing scientific data collected in the region.

\section{Methodology}

A survey instrument was developed to access public priorities, attitudes and concerns about water resource issues in the Pacific Northwest. The survey was administered to the general public in 2002, 2007 and 2012 to evaluate changes over time. The specific survey questions discussed in this article deal with activities that the public associate with water pollution. The survey target audience was a representative sample of the 9,000,000 adult residents of the four Pacific Northwest states (Alaska, Idaho, Oregon, Washington).

In addition, demographic information, including state of residence, community size, length of time residing in the region, gender, age, and educational level were also collected from survey respondents.

In 2012 a target of 950 completed questionnaires was chosen as the survey goal to result in a sampling error of 4 to $6 \%$ [16]. The survey process was designed to receive a completed survey return rate in excess of $50 \%$. Addresses were obtained from a professional social sciences survey company (SSI, Norwich, CT). Four mailings were planned to achieve the $50 \%$ return rate [17]. The mailing strategy used was identical to that of the 2002 and 2007 samplings [18].

Surveys were actually sent to 2,126 residents; however, because address changes, deaths of people on the mailing list and delivery problems, the actual sample population was 1,886 . The survey process was designed to receive a completed survey return rate in excess of 50\%. If more than 943 surveys were returned completed, then sampling error could be assumed to be less than $5 \%$ $[16,17]$.

It only took three mailings were to achieve this target return rate of 50\%. The first mailing, which took place in May 2012, included the water issues survey form, a business reply envelope, and a cover letter that: (1) identified the survey's authors; (2) explained the purpose of the survey; (3) assured the respondent of anonymity; and (4) asked the respondents to fill out and return the survey via the business reply envelope. The second mailing occurred 5 weeks later (June 2012) and consisted of a postcard that stressed the importance of the survey and remind the respondent to fill out and return the survey sent out in the first mailing. Five weeks later (August 2012), the third mailing was sent to residents who did not respond to the first or second mailing. This mailing 
included a reminder letter, another copy of the water issues survey, and a business reply envelope.

Survey answers were coded and entered into Microsoft Excel. Missing data were excluded from the analysis. The data were analyzed at two levels using SAS [19]. The first level of analysis generated frequencies, while the second level evaluated the impacts of demographic factors. Significance $(\mathrm{P}<0.05)$ to demographic factors was tested using a chi-square distribution [20].

\section{Results and discussion}

The survey methodology used in the study was not designed to be unique, but rather to be used as a tool to ascertain useful information. The survey methodology is designed to track the origins of water pollution in surface waters as seen by the general public. The pollution blame as assessed by the public will be matched with actual scientific data showing the actual sources of water pollution. Appropriate education programs will be developed for Pacific Northwest audiences based on this information.

The 2012 Pacific Northwest Water Issues Survey achieved a return rate of $54.1 \%(1,021$ either fully or partially completed and returned out of 1,886). Fifty-five percent of the survey respondents were male. Over $38 \%$ of survey respondents lived in communities of more than 100,000 people. Conversely, $16 \%$ of respondents lived in towns with less than 7,000 people. Thirty-nine percent of respondents had lived in the Pacific Northwest all of their lives. Ninety percent of survey respondents were high school graduates. Overall, the demographics of the survey respondents (except for gender) closely reflected the actual demographics of the region. Consequently, when coupled with the low sampling error of the survey, respondents are often equated to residents in the following discussion.

Although the data is not presented in this paper, the 2002, 2007 and 2012 surveys showed that over $90 \%$ of Pacific Northwest respondents considered clean drinking water, clean rivers, and clean groundwater as high priority. The public is very concerned about water pollution - and this concern has been significant for the last 12 years. The 2012 survey data will be emphasized in this paper; however, a comparison with results obtained in the 2002 and 2007 surveys will be made in the summary and recommendations section of this paper.

\subsection{Public identification of major polluters}

Survey respondents were asked to select three major polluters of surface waters from a menu of 13 potential sources. More than one-quarter of survey respondents listed industry, animal agriculture, cropping systems agriculture, storm water runoff and erosion from roads and/or construction sites as major water pollution sources (Table 1). Another fifth of the respondents to the 2012 Pacific Northwest Water Resource Issues Survey considered new suburban development and septic systems major water polluters. Lesser numbers of survey respondents linked forestry, runoff from home landscapes, oil wells and/or 
mining, waste water treatment plants and landfills to water pollution. Conversely, only $6.9 \%$ of the survey respondents thought that military bases were one of the three major contributors to surface water pollution.

Table 1: Response to the question "In your opinion which of the following are most responsible for existing pollution problems in rivers and lakes in your state (check up to three items)" based on the 2012 PNW survey.

Industry

Agriculture - animals

Agriculture - crops

Storm-water runoff

Erosion - roads/construction

New suburban development

Septic systems

Forestry

Runoff from home landscapes

Oil wells and mining

Wastewater treatment plants

Landfills

Military bases
35.4

32.0

30.5

29.2

25.5

21.9

21.8

18.1

17.1

16.4

15.1

14.0

6.9

Significant interactions between polluting activity and where survey respondents lived (WL), town size (TS), length of time living in the region (PNW), gender (GDR), age (AGE), and formal education level (ED) are shown in Table 2. Formal education level affected responses to the polluting activities of cropping systems agriculture, new suburban development, wastewater treatment and landfills. The significant interactions identified in Table 2 will be discussed in this paper.

Based on the 2012 survey the public believes that industry agriculture and storm water are the activities that are most responsible for the degradation of surface water quality. For the most part, regulatory agencies would agree with these top three choices; however, they would likely change the ranking from most to least negative impact on surface waters to: agriculture, storm water runoff and industry.

\subsection{Industry}

Industry was the most commonly cited polluter of surface water in the Pacific Northwest (35.4\%). The demographic factors of where the survey respondent lived (WL) and town size (TS) impacted the likelihood of industry being cited as 
Table 2: Significance of interactions between polluting activity and the demographic factors of where people live (WL), town size (TS), length of time in the Pacific Northwest (PNW), gender (GDR), age (AGE) and formal education (ED) based on responses to the 2012 PNW survey.

\begin{tabular}{lllllll}
\hline \multirow{2}{*}{ Polluting activity } & \multicolumn{7}{c}{ Significance of interaction } \\
\cline { 2 - 6 } & WL & TS & PNW & GDR & AGE & \multirow{2}{*}{ ED } \\
\hline Industry & .03 & .01 & NS & NS & NS & NS \\
Ag - animals & NS & NS & NS & NS & .04 & NS \\
Ag - crops & NS & NS & NS & .04 & NS & .06 \\
Storm-water & NS & NS & NS & NS & NS & NS \\
Erosion & NS & NS & NS & .0001 & .01 & NS \\
Suburban dev. & NS & .04 & NS & NS & .01 & .04 \\
Septic systems & NS & NS & NS & NS & NS & NS \\
Forestry & NS & NS & .02 & NS & NS & NS \\
Home landscapes & NS & NS & NS & NS & NS & NS \\
Oil and mining & NS & .03 & .0001 & NS & NS & NS \\
Waste-water treatment & NS & NS & NS & NS & NS & .009 \\
Landfills & NS & NS & NS & .01 & NS & .009 \\
Military bases & NS & NS & NS & NS & NS & NS \\
& & & & & & \\
\hline
\end{tabular}

a major pollution source. People living inside city limits were most likely to list industry as a major polluter. In addition, over $35 \%$ of survey respondents living in communities of more than 7,000 selected industry as a major surface water polluter. Conversely, only 29.9 and $24.8 \%$ of people living in communities of 3,500 to 7,000 and in communities of less than 3,500 listed industry as a major polluter, respectively (Table 3 ). Basically, the public in larger communities is more likely to blame industry for water quality problems.

Table 3: Interaction between likelihood of blaming industry for surface water pollution and community size based on the 2012 PNW survey.

Community size Percent citing

More than 100,000

25,000 to 100,000

40.1

7,000 to 25,000

37.6

3,500 to 7,000

29.9

Less than 3,500

24.8 
In the case of industrial pollution public perception is not on track with reality. While industry is responsible for some surface water pollution in the region, legislation contained in the federal Clean Water Act of 1972 (CWA), Safe Drinking Water Act of 1974 (SDWA), and Resource Conservation and Recovery Act of 1976 (RCRA) has resulted in a large decline of pollutants from industry ending up in surface water of the region over the last 40 years.

\subsection{Agriculture}

Both animal agriculture and cropping systems agriculture were cited by more than $30 \%$ of the survey respondents as being major surface water pollutant sources in the Pacific Northwest. There was an interaction between the demographic factor of respondent age and the response to animal agriculture. Here respondents that were younger than 40 and older than 60 were more likely to blame animal agriculture for surface water pollution than people between the ages of 40 and 60 (Table 4). The explanation for this interaction is not clear.

Table 4: Interaction between likelihood of blaming animal-based agriculture for surface water pollution and respondent age based on the 2012 PNW survey.

Respondent age Percent citing

Less than 30

30 to 39

39.5

40 to 49

26.1

50 to 59

24.4

60 to 69

37.5

More than 70

When cropping systems agriculture is evaluated as a pollution source interactions for the demographics of gender and formal education level of the respondent were observed (Table 2). Males were more likely to associate cropping systems agriculture with the pollution of rivers and lakes than female respondents (32.6\% vs. $25.9 \%$ ). In addition respondents with college B.A., B.S. or advanced degrees were more likely to associate cropping systems agriculture with surface water pollution than people with high school diplomas or some college (Table 5).

The public perception that agriculture is responsible for significant surface water pollution is correct. In fact agriculture receives less blame than it should based on environmental agency data collected at the state level in the Pacific Northwest. Agriculture is the major source of soil erosion in the region, which in turn degrades surface water quality. In addition agriculture is the primary source of nutrient and pesticide additions to surface waters in the region. Based on 
recent research and regulatory data agriculture is the major contributor to surface water degradation in the Pacific Northwest. Based on this data and the survey responses it appears that over $60 \%$ of survey respondents are unaware of this.

Table 5: Interaction between the likelihood of blaming cropping systemsbased agriculture for surface water pollution and formal educational level of respondents based on the 2012 PNW survey.

Respondent education level Percent citing

Less than high school diploma

High school diploma

Some college

26.0

College graduate

33.9

Advanced college degree

36.9

\subsection{Storm water runoff}

As a major pollution source for surface waters storm water was the fourth highest cited activity. Almost 30\% of the Pacific Northwest Survey respondents rated storm water as one of the three largest sources contributing to pollution. There were no interactions attributed to demographic factors for storm water runoff.

Storm water is a pollution issue that receives a lot of public exposure in this region. The average urban resident of the region has seen the fish decals placed on storm water drains to discourage the disposal of polluting wastes. In the area surrounding the Puget Sound, the most populated area in the region, the public has a high awareness level of the potential negative impacts of poor storm water disposal practices. This has caused the storm water issue to be of widespread concern and has hopefully encouraged individual voluntary action to reduce the negative impact of storm water disposal.

\subsection{Erosion from roads and construction sites}

Over one fourth of the survey respondents cited erosion as one of the three major sources of surface water pollution (Table 1). When erosion is evaluated as a pollution source interactions for the demographic factor of gender and age of the respondent were observed (Table 2). Females were more likely to associate erosion with surface water pollution than males (35.3\% vs. $20.7 \%)$. In addition respondent age also affect the choice of erosion as a major pollutant (Table 6). Survey respondents less than 30 years old were almost twice as likely to cite erosion as respondents from all other age groups. 
Table 6: Interaction between the likelihood of blaming erosion from roads and construction sites for surface water pollution and respondent age based on the 2012 PNW survey.

Respondent age Percent citing

Less than 30

30 to 39

40 to 49

27.0

50 to 59

26.2

60 to 69

More than 70

21.3

Erosion along roads or at construction sites is something that many individuals have observed first hand. It is likely that people who have observed significant erosive events along the road or by driving by construction sites were impressed with the scale of soil loss and translated their observation into significantly negative impacts to surface water.

\subsection{Other polluting activities}

Less than $22 \%$ of the survey respondents selected the other eight choices as being major pollution sources for surface waters of the region. New suburban development was selected as a major pollutant by $21.9 \%$ of the survey respondents. Here interactions with the demographic factors of community size, age and formal education level affected respondent answers. People living in communities of more than 100,000 were more likely to cite new suburban development. People between the ages of 40 and 69 were the most likely to select new suburban development as a major surface water pollutant source. In addition, residents with some college education were most likely to link surface water pollution with new suburban development. Conversely, without a high school diploma were least likely to link new suburban development with water pollution.

There was an interaction between community size and the linkage with oil wells and/or mining to surface water pollution; however, the interpretation of this interaction is difficult.

As a demographic factor, formal education level affected responses to waste water treatment and landfill activities. Basically, the most and least educated groups were less likely to tie waste-water treatment plants to surface water pollution. In contrast, increasing levels of formal education made respondents less likely to blame landfills as a major source of surface water pollution. 


\section{Conclusions and recommendations}

Residents of the Pacific Northwest have always considered water to be the most important environmental issue impacting them. Consequently, there has always been strong support for both regulatory and voluntary actions to protect the region's river, lakes, wetlands, estuaries and bays. Based on this series of needs assessment surveys over $95 \%$ of the public in Idaho, Oregon, Washington and Alaska have consistently rated clean rivers as being a very or extremely import issue. In contrast, other important global issues including air pollution, food safety, climate change, deforestation and clean energy are supported as a very or extremely important by only $23,62,50,45$ and $40 \%$ of the region's residents, respectively.

In addition, based on the 2002, 2007 and 2012 survey data the public is literate about water issues and is willing to share their concerns and beliefs. These beliefs may not mesh with current research data however. For instance, industry, because of legislation passed since 1970 is not the major polluter of rivers and lakes in the region. Many traditional polluting activities are regulated by federal and/or state legislation. For instance industrial plants, wastewater treatment and many activities that create point source erosion events are highly regulated and thus these activities do not contribute the volume of pollutants to surface waters that they once did. Conversely, agricultural pollution is voluntarily regulated with the use of best management practices (BMPs) to reduce sediment, nutrient and pesticide delivery to surface water systems. Consequently, agriculture is the major polluter of many surface bodies of water in this region.

Although pollution related to storm water discharge is widely recognized by the public in urban areas, reduction in the types and quantities of things going into storm drains in the region is largely a voluntary activity.

In summary the public has good insight into the activities that degrade surface waters. Based on the presented data we propose the following three recommendations:

1. Provide educational opportunities so that public perceptions about surface water pollution sources match up with monitoring data collected by regulatory agencies. The outreach component of land grant universities, Extension, should lead this effort.

2. Have Extension, the outreach branch of land grant universities, invest more heavily in environmental education programs targeted at children in grades K-12. These students have the potential to take home values and ideas that will encourage parents to be more proactive to protect surface water quality.

3. Show the public how they can make a difference in pollution reduction. Encourage citizens to become active at the local level to further improve surface water quality. Promote both voluntary actions and citizen involvement to pass reasonable regulations that will further enhance surface water quality. 


\section{Acknowledgement}

The authors would like to acknowledge USDA-NIFA for supporting this survey work over the last 12 years as a portion of the Pacific Northwest Water Resources Coordination Project.

\section{References}

[1] Cooper, C. M. Biological effects of agriculturally derived surface water pollutants on aquatic systems-a review. Journal of Environmental Quality, 22(3), 402-408, 1993.

[2] Schröder, J. J., Scholefield, D., Cabral, F., \& Hofman, G. The effects of nutrient losses from agriculture on ground and surface water quality: the position of science in developing indicators for regulation. Environmental Science \& Policy, 7(1) 15-23, 2004.

[3] Randall, G. W., \& Mulla, D. J. Nitrate nitrogen in surface waters as influenced by climatic conditions and agricultural practices. Journal of Environmental Quality, 30(2), 337-344, 2001.

[4] Correll, D. L. The role of phosphorus in the eutrophication of receiving waters: A review. Journal of Environmental Quality, 27(2), 261-266, 1998.

[5] Carpenter, S. R., Caraco, N. F., Correll, D. L., Howarth, R. W., Sharpley, A. N., \& Smith, V. H. Nonpoint pollution of surface waters with phosphorus and nitrogen. Ecological applications, 8(3), 559-568, 1998.

[6] Morley, S. A., \& Karr, J. R. Assessing and restoring the health of urban streams in the Puget Sound Basin. Conservation Biology, 16(6), 14981509, 2002.

[7] Reinelt, L., Horner, R., \& Azous, A. Impacts of urbanization on palustrine (depressional freshwater) wetlands-research and management in the Puget Sound region. Urban Ecosystems, 2(4), 219-236, 1998.

[8] Beschta, R. L. Long-term patterns of sediment production following road construction and logging in the Oregon Coast Range. Water Resources Research, 14(6), 1011-1016, 1978.

[9] Trombulak, S. C., \& Frissell, C. A. Review of ecological effects of roads on terrestrial and aquatic communities. Conservation biology, 14(1), 1830, 2000.

[10] Anonymous, Voluntary action needed to protect water quality, Journal of Environmental Health, 53:6, 1990.

[11] May, P.J., Marine facilities and water quality: Regulatory versus voluntary approaches, Coastal Management, 31:297-317, 2003.

[12] Neufield, D.A., An ecosystem approach for groundwater: The case of Waterloo Region, Ontario, Canada, Hydrogeology Journal, 8:239-250, 2000.

[13] Koski, C. \& May, P.J., Interest and implementation: Fostering voluntary regulatory actions, Journal of Public Administration Research and Theory, 16:329-349, 2006. 
[14] Mahler, R. L., Simmons, R., Sorensen, F., \& Miner, J.R., Priority water issues in the Pacific Northwest, Journal of Extension, [On-line], 42(5). Article 5RIB3. Available at: http://www.joe.org/joe/2004october/rb3.php, 2004.

[15] Mahler, Robert L., Smolen, Michael D., Borisova, Tatiana, Boellstorff, Diane E., Adams, Damien, C. \& Sochacka, Nicola W. The national water survey needs assessment program. Natural Sciences Education, 42(1): 98103, 2013.

[16] Salent, P., \& Dillman, D., How to Conduct Your own Survey. John Wiley and Sons, Inc. New York, New York, 1994.

[17] Dillman, D., Mail and Internet Surveys: The Tailored Design Method. John Wiley and Sons, Inc. New York, New York, 2000.

[18] Mahler, R.L., Gamroth, M., Pearson, P., Sorenson, F., Barber, M.E. \& Simmons, R., Information sources, learning opportunities and priority water issues in the Pacific Northwest, Journal of Extension [On-line], 48(2). Article 2RIB2. Available at: http://www.joe.org/joe/2010april /rb2.php, 2010.

[19] SAS Institute Inc., SAS Online Document 9.1.3. Cary, North Carolina: SAS Institute Inc., 2004.

[20] Babbie, E., The practice of social research. 3rd edition. Wadsworth Publishing Company. Belmont, CA. pp. 359, 424, 1983. 